\title{
Novi petrokemijski procesi na temelju izravne pretvorbe metana
}

\section{F. Faraguna i A. Jukić*}

\author{
Zavod za tehnologiju nafte i petrokemiju \\ Fakultet kemijskog inženjerstva i tehnologije Sveučilišta u Zagrebu \\ Marulićev trg 19, 10000 Zagreb
}

\begin{abstract}
\| Sažetak
Petrokemija je grana kemije i kemijskog inženjerstva koja proučava reakcije i procese dobivanja i svojstva proizvoda iz naftnih prerađevina i prirodnoga plina, a koji ne služe kao goriva ili maziva. U svojim početcima petrokemija, odnosno organska kemijska industrija, temeljila se na etinu i Reppeovim sintezama. Danas su osnovne petrokemikalije olefini i aromatski ugljikovodici, s težnjom razvoja novih procesa i sve veće uporabe sinteznog plina, metana i drugih alkana kao ishodnih sirovinskih komponenti. U ovom radu dan je pregled reakcija i novih procesa izravne pretvorbe metana u vrjednije petrokemijske proizvode. Kroz pojedina poglavlja u radu su detaljnije opisane reakcije parcijalne oksidacije metana, dehidroaromatizacije metana te oksidacijskog i neoksidacijskog spajanja metana u više ugljikovodike.
\end{abstract}

\author{
\| Ključne riječi \\ Izravna pretvorba, metan, novi petrokemijski procesi
}

\section{Uvod}

Metan je najjednostavniji ugljikovodik čija se molekula sastoji od jednog ugljikova i četiriju vodikovih atoma. Talište metana je 90,6 K, a vrelište 111,6 K te je pri sobnoj temperaturi plin bez boje i mirisa. Metan je glavna komponenta prirodnog (zemnog) plina, a najčešće se upotrebljava kao energent/gorivo te u kemijskoj industriji kao temeljna petrokemijska sirovina. ${ }^{1} \mathrm{~S}$ obzirom na to da je većina nalazišta prirodnog plina udaljena od područja njegove pri mjene, potrebno ga je transportirati plinovodima, što poskupljuje cijenu metana. Zbog neekonomičnosti udaljenog transporta ili nepostojanja odgovarajuće infrastrukture, prirodni se plin na nalazištima nafte često ispušta u atmosferu ili spaljuje na bakljama (engl. gas flaring; prema podacima Svjetske banke oko $130 \mathrm{mlrd}$. $\mathrm{m}^{3}$ godišnje, mjereno pri normalnim uvjetima). ${ }^{2} \mathrm{U}$ želji da se izbjegne skupi transport prirodnog plina i ekonomski gledano taj plin bolje

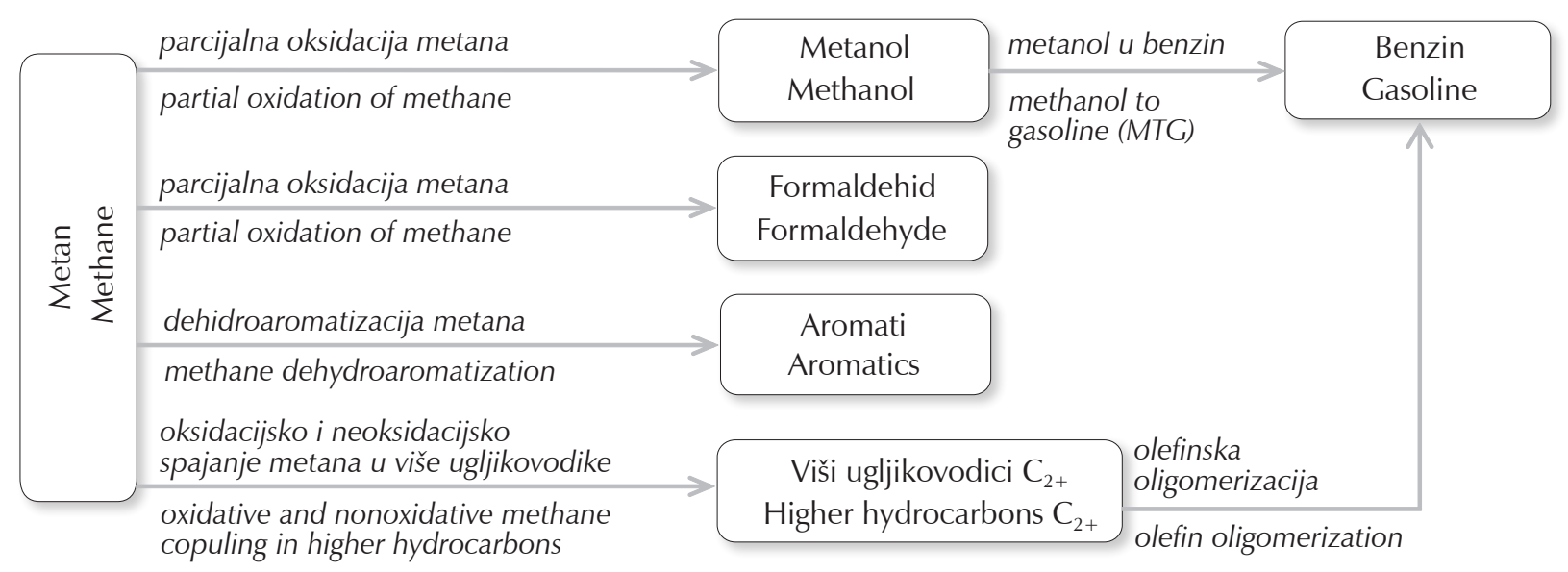

Slika 1 - Reakcijski putovi izravne pretvorbe metana u petrokemijske proizvode

Fig. 1 - Reaction pathways of direct methane conversion into petrochemical products 


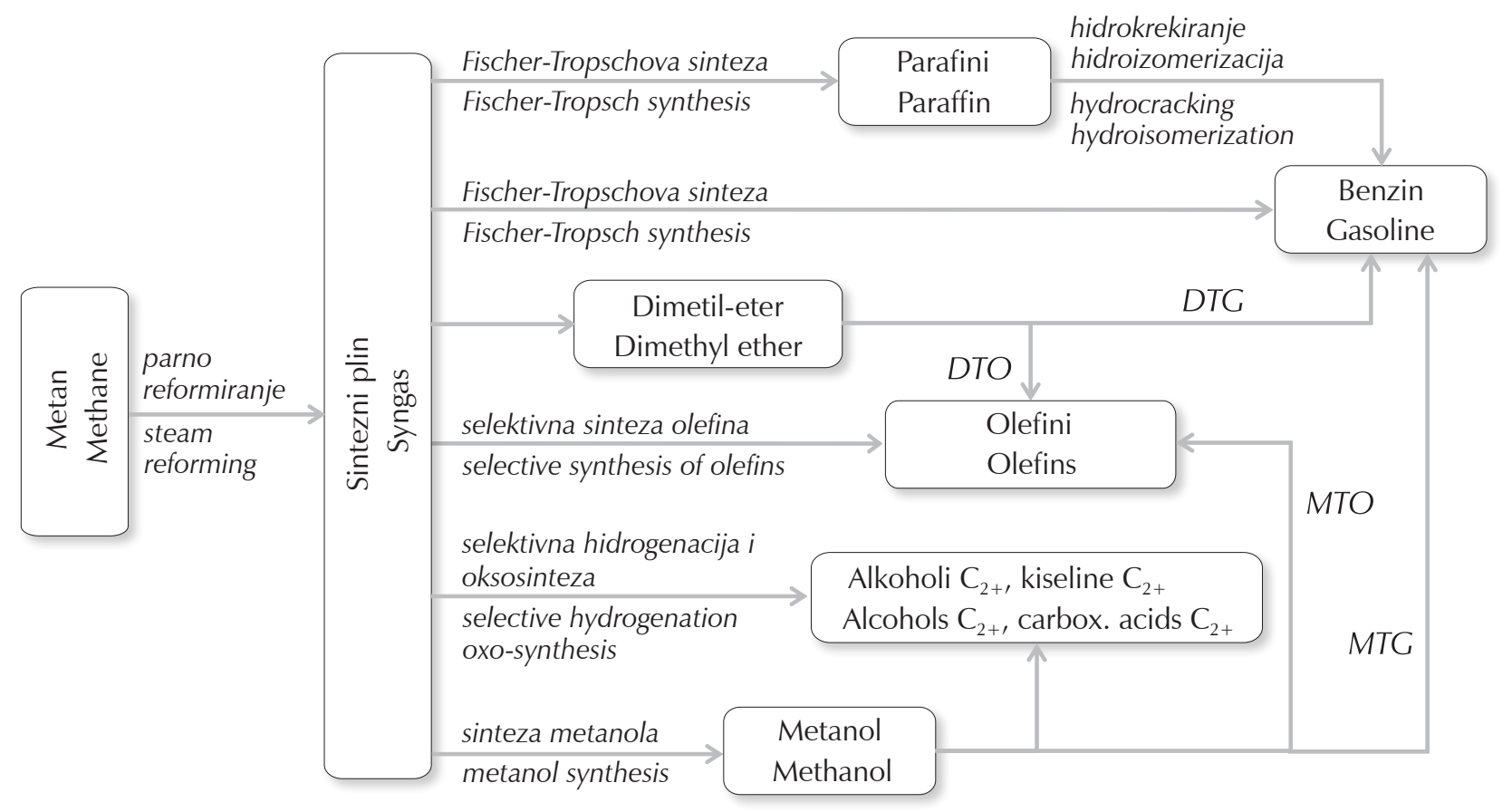

Slika 2 - Reakcijski putovi neizravne pretvorbe metana u petrokemijske proizvode

Fig. 2 - Reaction pathways of indirect methane conversion into petrochemical products

iskoristi, teži se proizvodnji vrjednijih kemikalija na samom nalazištu.

Metan je simetrična i stabilna molekula kojoj treba dovesti energiju da bi došlo do pucanja stabilne $\mathrm{C}-\mathrm{H}$ veze (435 $\mathrm{kJ} \mathrm{mol}^{-1}$ ) i daljnje reakcije za dobivanje željenog produkta. S obzirom na način dovođenja energije, reakcijski put može biti izravna (slika 1) i neizravna (slika 2) pretvorba metana u petrokemijske proizvode.

Izravna pretvorba metana obuhvaća sljedeće reakcije: parcijalnu oksidaciju metana u metanol ili formaldehid, dehidroaromatizaciju metana u aromatske ugljikovodike (aromate) te oksidacijsko i neoksidacijsko spajanje metana u više ugljikovodike. Dobiveni petrokemijski proizvodi mogu se dalje prevesti u benzin, katalitičkim procesima pretvorbe metanola (engl. Methanol to Gasoline, MTG) i olefinskom oligomerizacijom viših ugljikovodika.

Kod neizravne pretvorbe metana najprije se iz metana parnim reformiranjem proizvodi sintezni plin, smjesa $\mathrm{CO} \mathrm{i} \mathrm{H}_{2}$ koji je osnova za daljnju sintezu petrokemijskih proizvoda. Iz sinteznog plina Fischer-Tropschovom sintezom mogu se proizvesti alkani (parafini) i benzin, dimetil-eter, selektivnom sintezom olefini, selektivnom hidrogenacijom i oksosintezom viši alkoholi i karboksilne kiseline te metanol. Iz navedenih primarnih petrokemijskih proizvoda daljnjim reakcijama prema slici 2 mogu se proizvesti benzin i olefini iz metanola i dimetil-etera, dok se hidrokrekiranjem i hidroizomerizacijom iz parafina proizvodi benzin. Viši alkoholi i kiseline proizvode se iz metanola.

\section{Izravna pretvorba metana}

Razvoj postupaka izravne pretvorbe metana od velikog je interesa jer bi se za dobivanje korisnih petrokemijskih proizvoda navedenim postupcima izbjegla uporaba energetski zahtjevnog procesa parnog reformiranja. Također bi se smanjila potreba za proizvodnjom olefina procesima parnog i katalitičkog krekiranja. Metan je kao stabilnu molekulu nepolarnog karaktera i bez funkcijskih skupina teško destabilizirati i potaknuti na reakciju. Za njegovu aktivaciju najčešće su potrebne visoke temperature ili oksidansi. Neki od prvih postupaka aktivacije upotrebljavali su kao katalizatore organometalne sustave, ${ }^{3-6}$ metalne ione u plinovitom stanju $\mathrm{u}^{7,8}$ i biokemijske sustave, ${ }^{9}$ pri čemu se aktivacija metana može provesti heterogenom, ${ }^{10-12}$ ili homogenom katalizom. ${ }^{13,14}$

Metode izravne pretvorbe dijele se na oksidacijske i neoksidacijske, ovisno o prisutnosti oksidansa. U neoksidacijske metode spadaju spajanje metana u više ugljikovodike (engl. Nonoxidative Coupling of Methane, NOCM) i neoksidacijska dehidroaromatizacija metana (engl. Nonoxidative Methane Dehydroaromatization, MDA). Na slici 3 prikazana je ovisnost izravne pretvorbe (konverzije) metana o temperaturi pretvorbe za navedene metode, u usporedbi s pirolizom metana na ugljik i vodik.

Oksidacijske metode izravne pretvorbe metana oksidacijsko su spajanje metana u više ugljikovodike (engl. Oxidative Coupling of Methane, OCM) i parcijalna oksidacija metana (engl. Partial Oxidation of Methane, POM). Dovođenjem energije, pri visokim temperaturama, kida se veza $\mathrm{C}-\mathrm{H}$ 
u metanu nakon čega reakcijom nastalih vrsta (radikala u plinovitom stanju) nastaju spojevi viših molekulskih masa, najčešće uz oslobađanje vodika. Nastali produkti imaju nižu energiju veze od metana zbog čega je njihov nastanak termodinamički ograničen, pa se postižu niska iskorištenja. Međutim, odvođenjem drugog produkta, najčešće vodika, kod neoksidacijskih metoda reakcijska ravnoteža može se pomicati prema produktima i povećati njihova iskorištenja. U oksidacijskim metodama oksidans (kisik) reagira s nastalim vodikom dajući vodu, čijim se odvođenjem iz reakcijskog sustava također postižu viša iskorištenja. Upotrebom oksidansa, zbog nastanka produkata s nižom energijom veze, može zbog različite kinetike biti u prednosti oksidacija ugljikovodika do $\mathrm{CO}$ i $\mathrm{CO}_{2}$. Kemijskom zaštitom ili selektivnim odvođenjem produkata može se smanjiti stupanj oksidacije i povećati iskorištenje na željenoj reakciji.

Metode izravne pretvorbe metana energijski i tehnološki zahtjevni su procesi koji su zasad zbog malih iskorištenja pri jednom prolazu kroz reaktor ekonomski neisplativi za primjenu u velikim industrijskim postrojenjima (za proizvodnju velikih količina).

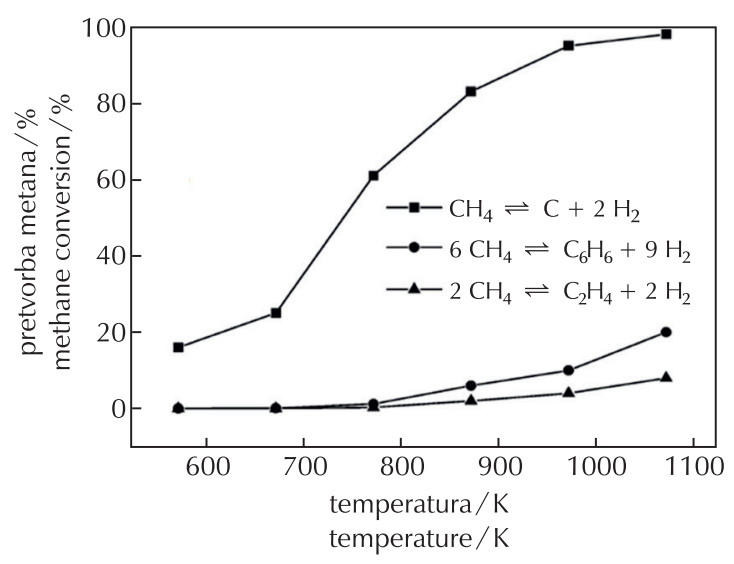

Slika 3 - Ovisnost pretvorbe metana o temperaturi za dane kemijske reakcije

Fig. 3 - Methane conversion dependence on temperature for given reaction

\section{Neoksidacijsko spajanje metana u više ugljikovodike}

Neoksidacijsko spajanje metana (NOCM) u više ugljikovodike shematski je prikazano na slici 4. NOCM je proces koji se sastoji od dvaju stupnjeva. ${ }^{15,16}$ Santen $i$ sur. ${ }^{15}$ su iz metana proizveli alkane $\mathrm{C}_{2}-\mathrm{C}_{6}$ pri atmosferskim tlaku preko mehanizma prikazanog na slici 5.

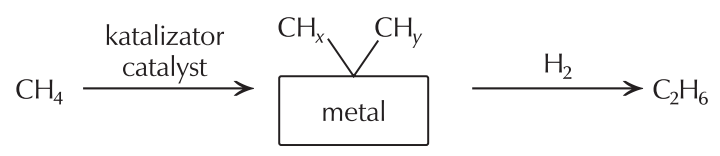

Slika 4 - Pojednostavljeni prikaz neoksidacijskog spajanja metana u više ugljikovodike

Fig. 4 - Simplified scheme for methane nonoxidative coupling to higher hydrocarbons

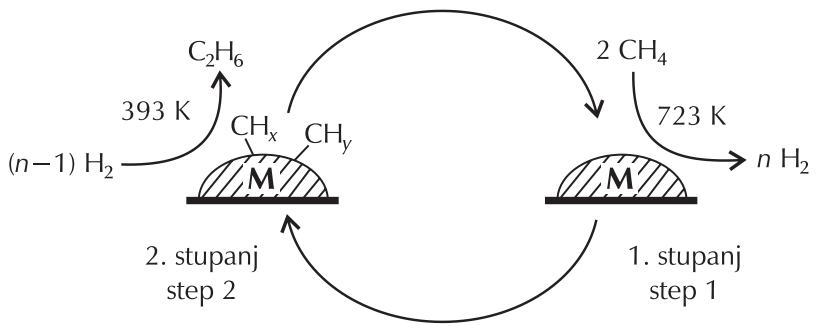

Slika 5 - Dvostupanjski proces dobivanja viših ugljikovodika iz metana prema Santenu i sur. ${ }^{15}$

Fig. 5 - Two-step methane nonoxidative coupling to higher hydrocarbons according to Santen et al. ${ }^{15}$

U prvom stupnju metan se razlaže na metalu iz 8. skupine periodnog sustava pri temperaturama od 450 do $800 \mathrm{~K}$ i veže se na njega. U drugom koraku iz nastalog spoja uz pomoć dovedenog vodika pri 300 - $400 \mathrm{~K}$ nastaju alkani koji se potom desorbiraju s metalne površine. Amariglio i sur., ${ }^{17-22}$ radeći s platinom, zaključili su da nastaju veze $\mathrm{C}-\mathrm{C}$ između kemisorbiranih vrsta $\mathrm{CH}_{x}$ u prvom stupnju, dok drugi stupanj uključuje njihovo hidrogeniranje i odvajanje od katalitičke površine. Dvostupanjski postupak proveden je primjenom niza katalizatora na osnovi prijelaznih metala. ${ }^{23-26} \cup$ slučaju da se umjesto vodika dovode olefini, navedeni proces treba provesti u tri stupnja kako ne bi došlo do istodobne adsorpcije metana i olefina na katalizatoru. Santen i sur. ${ }^{27}$ predložili su reakcije prikazane na slici 6 .

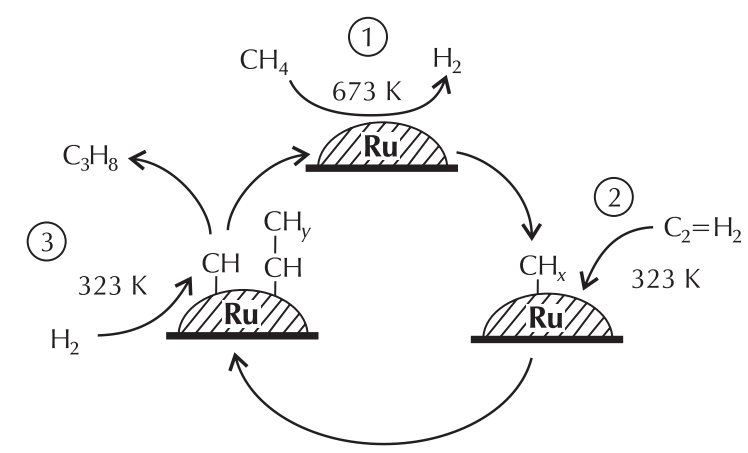

Slika 6 - Reakcijski koraci u NOCM-u s olefinima: 1) adsorpcija metana i njegova disocijacija uz otpuštanje vodika pri višim temperaturama, 2) adsorpcija etena pri nižim temperaturama, 3) spajanje adsorbiranih vrsta u prisutnosti vodika i desorpcija propana ${ }^{27}$

Fig. 6 - Reaction steps in methane nonoxidative coupling to higher hydrocarbons with olefins: 1) adsorption of methane and its dissociation at higher temperatures, 2) adsorption of ethene at lower temperatures, 3) coupling of adsorbed species in presence of hydrogen and desorption of propane ${ }^{27}$

Prvi korak je adsorpcija metana i njegova disocijacija na katalizatoru (prijelazni metal) pri višim temperaturama (473 - 823 K). U drugom koraku olefini se koadsorbiraju na katalizatoru pri nižim temperaturama (293 - 373 K) nakon čega slijede hidrogenacija i stvaranje te otpuštanje višeg homologa. ${ }^{27}$ lako je za adsorpciju i disocijaciju metana na katalizatoru potrebna relativno mala energija 
$(25-60 \mathrm{~kJ})$, proces je potrebno voditi pri višim temperaturama radi povećanja brzine procesa. Odvijanjem procesa pri još višim temperaturama na katalizatoru nastaje neaktivni koks. Navedenim postupkom aktivacije metana i pripreme viših ugljikovodika izbjegnuta je degradacija i deaktivacija nastalih adsorbiranih viših ugjjikovodika pri višim temperaturama.

Prilikom vezivanja metana na površinu metala mogu nastati tri različite ugljikove strukture, karbenska $\left(\mathrm{C}_{\alpha}\right)$, amorfna $\left(C_{\beta}\right)$ i grafitna $\left(C_{\gamma}\right)$. Navedeni ugljici razlikuju se prema temperaturi potrebnoj za njihovu hidrogenaciju. Najreaktivniji je $C_{\alpha}$ koji se može hidrogenirati pri $323 \mathrm{~K}, \mathrm{C}_{\beta}$ je manje reaktivan i može se hidrogenirati u području od $373 \mathrm{~K}$ do $573 \mathrm{~K}$, a njegovom hidrogenacijom viši ugljikovodici dobivaju se samo u tragovima. Najmanje je reaktivan $\mathrm{C}_{\gamma}$ za čiju su hidrogenaciju potrebne temperature više od $673 \mathrm{~K}$, a njegovom hidrogenacijom može se dobiti samo metan. Cilj je proizvesti što više ugljika $C_{\alpha}$ jer je jedino on zaslužan za nastajanje viših ugljikovodika. Eksperimentalno je utvrđeno da je pri maloj pokrivenosti površine ugljikovim vrstama na katalizatoru prisutan najveći udjel ugljika $\mathrm{C}_{\alpha \prime}$ dok se povećanjem pokrivenosti povećava udjel $\mathrm{C}_{\gamma} \cdot{ }^{15}$

Bradford ${ }^{28}$ je radeći s katalizatorima na bazi platine i rutenija primijetio da povećanjem tlaka dolazi do grananja i širenja raspodjele molekulskih masa dobivenih produkata. Primjenom rutenija na podlozi od miješanih metalnih oksida povećanjem tlaka povećao se sadržaj metilpentana i metilbutana, dok u slučaju platine na podlozi od miješanih metalnih oksida prevladava sinteza $\mathrm{C}_{4}$-produkata.

Kako bi smanjili količinu "duboko" disociranog metana na metalnim česticama tijekom dvostupanjskog procesa, Guczi $i$ sur. ${ }^{29-31}$ predložili su jednostupanjski proces. $U$ tom procesu metan se u pulsevima ispušta iznad katalizatora $\mathrm{Pd}-\mathrm{Co} / \mathrm{SiO}_{2}$ ili Pt-Co/NaY u prisutnosti smjese vodika i helija. ${ }^{29,30}$

Neoksidacijskim spajanjem metana u više ugljikovodike jednostupanjskim ili dvostupanjskim procesom postižu se niske konverzije nezanimljive za komercijalnu primjenu ovih procesa. Radi povećanja iskorištenja i reaktivnosti te prevladavanja termodinamičkih ograničenja primijenjeno je pobuđenje plazmom. Kao produkti većinom nastaju $\mathrm{C}_{2} \mathrm{H}_{6}, \mathrm{C}_{2} \mathrm{H}_{4}$ i $\mathrm{C}_{2} \mathrm{H}_{2}$, a ovisno o vrsti plazme i reakcijskim uvjetima selektivnosti prema određenoj molekuli mogu biti različite. ${ }^{32-34}$ Zhijian i sur. ${ }^{34}$ u reaktoru s plazmom dobivenom mikrovalovima pri atmosferskom tlaku iz smjese metana i vodika dobili su $76 \%$-tnu konverziju sa selektivnošću prema etinu od $88 \%$ i etenu od $6 \%$. Glavni nedostatak upotrebe plazme u reakciji NOCM je ukupno nisko energijsko iskorištenje.

\section{Neoksidacijska dehidroaromatizacija metana}

Neoksidacijska dehidroaromatizacija metana (MDA) je termodinamički gledano povoljniji proces od neoksidacijskog spajanja metana u više ugljikovodike (slika 2). Navedena reakcija pojednostavljeno se može prikazati reakcijskom shemom na slici 7 .

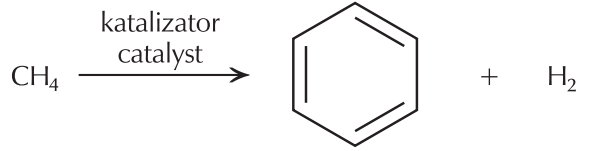

Slika 7 - Pojednostavljeni prikaz reakcije MDA

Fig. 7 - Simplified scheme for nonoxidative methane dehydroaromatization

Kataliziranom reakcijom MDA iz metana kao krajnji produkt nastaju aromatski spojevi i vodik. Wang i sur. ${ }^{36}$ prvi su proveli uspješnu neoksidacijsku dehidroaromatizaciju metana na prijelaznim metalima. Upotrijebili su zeolitni katalizator ZSM-5, koji su preveli u kiseli oblik HZSM-5 te mu dodali molibdenove i cinkove ione. Uz cinkove ione dobili su konverziju metana $3 \%$, dok je uz molibdenove ione postignuta konverzija 7,3\%. U oba slučaja selektivnost prema benzenu bila je $100 \%$. Daljnjim istraživanjima navedenog sustava zaključeno je kako je najbolji način pripreme katalizatora impregniranjem te da su tunelasta struktura, kiselost zeolita, valencija i položaj molibdenovih iona presudni za kvalitetu katalizatora. ${ }^{37,38}$ Navedena saznanja potaknula su cijeli niz istraživanja koja su se bavila zeolitom HZSM5, a ona su se posebno usredotočila na: a) modificiranje katalizatora Mo/HZSM-5 i optimizaciju reakcijskih uvjeta, b) interakciju prijelaznih metalnih iona i zeolitne podloge, c) proučavanje aktivnih mjesta i reakcijskog mehanizma i d) formiranje ugljikovih naslaga i njihov utjecaj na reakciju.

Solymosi i sur. ${ }^{39-42}$ ispitivali su cijeli niz katalizatora pripremljenih mijenjanjem molibdenskog prekursora $\left(\mathrm{MoO}_{3}\right.$, $\mathrm{K}_{2} \mathrm{MoO}_{4}, \mathrm{Mo}_{2} \mathrm{C}, \mathrm{Mo}, \mathrm{MoO}_{2}$ ) i nosioca $\mathrm{SiO}_{x}, \mathrm{Al}_{2} \mathrm{O}_{3}$, HZSM-5, $\mathrm{TiO}_{2}, \mathrm{MgO}$ ). Utvrđeno je kako je HZSM-5 najbolji nosilac i da priprema katalizatora značajno utječe na njegovu izvedbu. Lunsford $i$ sur. ${ }^{43}$ istraživali su utjecaj prijelaznih metala, odnosno vrstu i udjel prijelaznog metala, način pripreme i obrade katalizatora te utjecaj kiselosti katalizatora na njegovu aktivnost. Utvrdili su da se aktivnost smanjuje u nizu: Mo $(18,3)>\mathrm{W}(10,8)>\mathrm{Fe}(5,7)>\mathrm{V}(3,9)>\mathrm{Cr}(1,5)$, pri čemu su brojevi u zagradama reakcijske brzine iskazane brojem molekula $\mathrm{CH}_{4}$ izreagiranih po atomu metala po satu. Impregniranjem su dobivani bolji rezultati, pri čemu su se prijelazni metali većinom smjestili na površini, dok je manji dio difundirao u pore zeolita. Xu i sur. ${ }^{44,45}$ dodali su u sustav još jedan prijelazni metal i ustanovili da dodatak volframa i cirkonija povećava konverziju metana, dok je dodatak vanadija smanjuje. Dodatak litija i fosfora smanjuje kiselost katalizatora. Prisutnost litija smanjuje selektivnost prema benzenu, ali povećava selektivnost prema etenu. ${ }^{37}$ Upotrebom rutenija u katalizatoru Mo-Ru/HZSM-5 bolje se reducira molibden i posljedično bolje dehidrogenira metan, što također poboljšava pretvorbu metana. ${ }^{42}$ Ichikawa $i$ sur. ${ }^{46}$ primijetili su da se dodatkom željeza ili kroma katalizatoru Mo/HZSM-5 poboljšava nastajanje aromata i ujedno smanjuje nastajanje koksa od $31 \%$ na $21 \%$. Lin i sur. ${ }^{37}$ istražili su utjecaj različitih vrsta zeolita u pripremi katalizatora na osnovi molibdena na kvalitetu reakcije MDA. Kvalitetu katalizatora korelirali su s njihovom strukturom te zaključili da su zeoliti na osnovi silicija i aluminija s dvodimenzionalnom strukturom i veličinom pora sličnom promjeru benzenove molekule dobra podloga za molibden tj. za izradu katalizatora za reakciju MDA. Kvaliteta ispitanih katalizatora smanjuje se u nizu: Mo/H-ZSM-11 
$>\mathrm{Mo} / \mathrm{H}-\mathrm{ZSM}-5>\mathrm{Mo} / \mathrm{H}-\mathrm{ZSM}-8>\mathrm{Mo} / \mathrm{H}-\beta>\mathrm{Mo} / \mathrm{H}-\mathrm{M}-$ $\mathrm{CM}-41>\mathrm{Mo} / \mathrm{H}-\mathrm{SAPO}-34 \mathrm{Mo} / \mathrm{H}-$ mordenit $\approx \mathrm{Mo} / \mathrm{H}-\mathrm{X}>$ $\mathrm{Mo} / \mathrm{H}-\mathrm{Y}>\mathrm{Mo} / \mathrm{H}-\mathrm{SAPO}-5>\mathrm{Mo} / \mathrm{H}-\mathrm{SAPO}-11$.

U literaturi je predložen niz mehanizama kojima bi se reakcija MDA mogla odvijati na katalizatoru Mo/HZSM-5, od kojih će neki biti prikazani ovdje. Prvi stupanj je disocijacija veze $\mathrm{C}-\mathrm{H}$ za koju Xu $i$ sur. ${ }^{47}$ predlažu odvijanje prema sljedećem mehanizmu:

$\mathrm{Mo}^{\mathrm{VI}}(=\mathrm{O})_{3}+{ }^{\delta-} \mathrm{H}-\mathrm{C}^{\delta+}-\mathrm{H}_{3} \rightarrow \mathrm{Mo}^{\mathrm{VI}}(=\mathrm{O})_{3}+\mathrm{H}^{-}+{ }^{+} \mathrm{CH}_{3}$.

Pretpostavlja se da čestice molibdenova oksida polariziraju vezu $\mathrm{C}-\mathrm{H}$ metana koji disocira na $\mathrm{CH}_{3}{ }^{+} \mathrm{i} \mathrm{H}^{-}$. Mjerenjima provedenim fotoelektronskom spektroskopijom rendgenskim zrakama utvrdili su da se $\mathrm{Mo}^{6+}$ reducira do $\mathrm{Mo}^{5+} \mathrm{i}$ $\mathrm{Mo}^{4+}$, pri čemu je veća koncentracija $\mathrm{Mo}^{4+}$. Predložili su da se reakcija dalje odvija prema mehanizmu:

$$
\begin{aligned}
& 2 \mathrm{H}^{-}+\mathrm{Mo}^{\mathrm{VI}}(=\mathrm{O})_{3} \rightarrow \mathrm{Mo}^{\mathrm{IV}}(=\mathrm{O})\left(-\mathrm{O}^{-}\right)_{2}+\mathrm{H}_{2} \\
& \mathrm{Mo}^{\mathrm{IV}}(=\mathrm{O})\left(-\mathrm{O}^{-}\right)_{2}+{ }^{+} \mathrm{CH}_{3} \\
& \rightarrow \mathrm{Mo}^{\mathrm{IV}}(=\mathrm{O})\left(-\mathrm{O}^{-}\right)(-\mathrm{OH})\left(=\mathrm{CH}_{2}\right) \\
& \mathrm{Mo}^{\mathrm{IV}}(=\mathrm{O})\left(-\mathrm{O}^{-}\right)(-\mathrm{OH})\left(=\mathrm{CH}_{2}\right)+{ }^{+} \mathrm{CH}_{3} \\
& \rightarrow \mathrm{Mov}^{2}(=\mathrm{O})_{2}(-\mathrm{OH})\left(-\mathrm{C}_{2} \mathrm{H}_{5}\right) \\
& \left.\mathrm{MoV}^{2}=\mathrm{O}\right)_{2}(-\mathrm{OH})\left(-\mathrm{C}_{2} \mathrm{H}_{5}\right) \rightarrow \mathrm{Mo}^{\mathrm{IV}}(=\mathrm{O})(-\mathrm{OH})_{2}+\mathrm{C}_{2} \mathrm{H}_{4} \text {. }
\end{aligned}
$$

Molibdenov karben formira se na mjestima $\mathrm{Mo}^{4+}$ reakcijom $\mathrm{s} \mathrm{CH}_{3}{ }^{+}$, a navedena se mjesta obnavljaju desorpcijom etena. Desorbirani eten $u$ daljnjoj reakciji prelazi u benzen:

$$
3 \mathrm{C}_{2} \mathrm{H}_{4} \rightarrow \mathrm{C}_{6} \mathrm{H}_{6}+3 \mathrm{H}_{2} \text {. }
$$

Lin $i$ sur. $^{37}$ predlažu da se reakcija odvija unutar pora HZSM-5 gdje uz molibdenove čestice postoje i jaka kiselinska područja. Navedeni mehanizam uključuje stvaranje $\mathrm{CH}_{3} \cdot$ radikala koji dimeriziraju u etan i eten. Eten se potom uz pomoć protona iz zeolita aromatizira u benzen:

$$
\begin{aligned}
& \mathrm{CH}_{4}\left(\mathrm{MoO}_{x} \mathrm{H}^{+}\right) \rightarrow \mathrm{CH}_{3}+\mathrm{H}^{\bullet} \\
& 2 \mathrm{CH}_{3}\left(\mathrm{MoO}_{x}\right) \rightarrow \mathrm{C}_{2} \mathrm{H}_{4}+\mathrm{H}_{2} \\
& 3 \mathrm{C}_{2} \mathrm{H}_{4}\left(\mathrm{H}^{+}\right) \rightarrow \mathrm{C}_{6} \mathrm{H}_{6}+3 \mathrm{H}_{2} .
\end{aligned}
$$

Provodeći reakciju na katalizatoru $\mathrm{MoO}_{3} / \mathrm{SiO}_{x}$ Solymosi $i$ sur. ${ }^{39}$ su $\mathrm{u}$ prvom stupnju reakcije iz metana dobili $\mathrm{CO}\left(\mathrm{CO}_{2}\right)$ i $\mathrm{H}_{2} \mathrm{O}$, što su opisali sljedećim mehanizmom:

$$
\begin{aligned}
& 3 \mathrm{MoO}_{3}+\mathrm{CH}_{4} \rightarrow \mathrm{CO}+2 \mathrm{H}_{2} \mathrm{O}+3 \mathrm{MoO}_{2} \\
& 4 \mathrm{MoO}_{3}+\mathrm{CH}_{4} \rightarrow \mathrm{CO}_{2}+2 \mathrm{H}_{2} \mathrm{O}+4 \mathrm{MoO}_{2} .
\end{aligned}
$$

Na reduciranom katalizatoru dolazi do (a) oksidacijske dehidrogenacije metana ili (b) postupnog raspada istog prema reakcijama:

a) $\mathrm{CH}_{4}+\mathrm{O}(\mathrm{s}) \rightleftharpoons \mathrm{CH}_{3}+\mathrm{OH}(\mathrm{s})$

$$
2 \mathrm{OH} \rightleftharpoons \mathrm{O}(\mathrm{s})+\mathrm{H}_{2} \mathrm{O}
$$

b) $\mathrm{CH}_{4} \rightleftharpoons \mathrm{CH}_{3}+\mathrm{H}$

$\mathrm{CH}_{3} \rightleftharpoons \mathrm{CH}_{2}+\mathrm{H}$

$\mathrm{CH}_{2} \rightleftharpoons \mathrm{CH}+\mathrm{H}$

$2 \mathrm{H} \rightleftharpoons \mathrm{H}_{2}$.
Nastale vrste mogu dati čitav niz produkata $\left(\mathrm{C}_{2} \mathrm{H}_{6}, \mathrm{C}_{2} \mathrm{H}_{4}\right.$, $\mathrm{C}_{3} \mathrm{H}_{8}$ ), a autori tvrde da stvaranje benzena ide preko etena dobivenog dehidrogenacijom etana. Mirodatos $i$ sur. ${ }^{48}$ na temelju rezultata svojih istraživanja smatraju da se reakcija MDA na katalizatoru odvija na različitim područjima. Navode da kisela mjesta podloge HZSM-5 potiču heterocikličku aktivaciju metana koja se odvija u prisutnosti molibdenova karbida ili reduciranih molibdenovih oksida. Ostale molibdenove vrste na površini ili u unutrašnjosti katalizatora zaslužne su za daljnju dimerizaciju etena. Predloženi mehanizam je sljedeći:

$$
\begin{aligned}
& 2 \mathrm{CH}_{4}\left(\mathrm{MoC}_{2} / \mathrm{MoO}_{\mathrm{x}}\right) \rightarrow 2 \mathrm{H}_{2}+\mathrm{C}_{2} \mathrm{H}_{4} \\
& 3 \mathrm{C}_{2} \mathrm{H}_{4}\left(\mathrm{H}^{+}\right) \rightarrow \mathrm{C}_{6} \mathrm{H}_{6}+2 \mathrm{H}_{2} .
\end{aligned}
$$

Radeći na sustavu s metanom i prirodnim plinom Pierella $i$ sur. ${ }^{49}$ predložili su sljedeće mehanizme pretvorbe metana u aromate:

$$
\begin{aligned}
& \mathrm{CH}_{4}+\mathrm{Mo} / \mathrm{HZSM}-5 \rightarrow{ }^{+} \mathrm{CH}_{3}+[\mathrm{Mo}-\mathrm{H}]^{5+} \\
& { }^{+} \mathrm{CH}_{3}+\mathrm{Mo} / \mathrm{HZSM}-5 \rightarrow \mathrm{Mo}^{5} \mathrm{CH}_{2} \\
& \mathrm{Mo}=\mathrm{CH}_{2}+\mathrm{CH}_{4} \rightarrow \mathrm{C}_{2} \mathrm{H}_{6} \rightarrow \text { aromati } \\
& \mathrm{Mo}=\mathrm{CH}_{2}+\mathrm{Mo}=\mathrm{CH}_{2} \rightarrow \mathrm{C}_{2} \mathrm{H}_{4} \rightarrow \text { aromati } \\
& \mathrm{Mo}=\mathrm{CH}_{2} \rightarrow \text { koks } \\
& \mathrm{CH}_{4}+\mathrm{Mo} / \mathrm{HZSM}-5+\text { koks } \rightarrow \text { aromati }
\end{aligned}
$$

Navedena istraživanja ukazuju na to da su molibdenove čestice (2 - 6\%) i zeolit HZSM-5 dva glavna sastojka, iako ne dovoljna, za dobru provedbu reakcije MDA. Prilikom postupka priprave katalizatora važan je također postupak impregniranja i kalciniranja. Razni prikazani mehanizmi reakcije MDA upućuju na važnost metalne čestice (molibdena) i kiselih područja bifunkcionalnog katalizatora s podlogom HZSM-5. Položaj metalnih čestica, na površini ili u porama katalizatora, također značajno utječe na reakciju MDA.

\section{Oksidacijsko spajanje metana u više ugljikovodike}

Reakcija oksidacijskog spajanja metana (OCM) izravan je i egzoterman proces, te kao takav nije ograničen termodinamičkim uvjetima poput prethodno navedenih neoksidacijskih reakcijskih putova. Prilikom oksidacijskog spajanja metana odvijaju se reakcije prikazane na slici 8 , a kao produkti mogu nastati etan ili eten. Reakcija potpune oksidacija je termodinamički povoljnija, pa je potrebno upotrebljavati katalizatore koji će favorizirati prvu reakciju.

$$
\begin{aligned}
& 2 \mathrm{CH}_{4}+\frac{1}{2} \mathrm{O}_{2} \stackrel{\begin{array}{c}
\text { katalizator } \\
\text { catalyst }
\end{array}}{\longrightarrow} \mathrm{C}_{2} \mathrm{H}_{6}+\mathrm{H}_{2} \mathrm{O} \\
& \mathrm{C}_{2} \mathrm{H}_{6}+\frac{1}{2} \mathrm{O}_{2} \stackrel{\begin{array}{c}
\text { katalizator } \\
\text { catalyst }
\end{array}}{\longrightarrow} \mathrm{C}_{2} \mathrm{H}_{4}+\mathrm{H}_{2} \mathrm{O}
\end{aligned}
$$

Slika 8 - Pojednostavljeni prikaz reakcije OCM

Fig. 8 - Simplified scheme for oxidative coupling of methane to higher hydrocarbons 
Među začetnicima istraživanja na navedenom području bili su Keller i Bhasin, ${ }^{50}$ koji su reakcijom OCM kataliziranom različitim metalnim oksidima na podlozi $\gamma-\mathrm{Al}_{2} \mathrm{O}_{3}$ sintetizirali etan i eten. U kvarcni reaktor naizmjenično su propuštali metan i zrak, pri čemu su se najaktivnijima pokazali oksidi antimona, olova, kositra, bizmuta, kadmija, telurija i mangana. Sustav $\mathrm{MnO}_{x} / \gamma-\mathrm{Al}_{2} \mathrm{O}_{3}$ bio je najaktivniji pri $1073 \mathrm{~K} \mathrm{~s}$ iskorištenjem na etanu i etenu $5 \%$ i pretvorbom (konverzijom) metana $14 \%$. Radeći na katalizatoru Li/MgO Lunsford i sur. ${ }^{51}$ zaključili su da kisik oduzima vodik iz metana, pri čemu se dva nastala plinovita radikala $\mathrm{CH}_{3}$ ' spajaju u etan. Uz navedeni katalizator dobivena je konverzija reakcije $37,8 \%$, sa selektivnošću prema $\mathrm{C}_{2} 50 \%$ i iskorištenjem $\mathrm{C}_{2} 19 \%$. Autori pretpostavljaju da su aktivna mjesta područja sa strukturama $\mathrm{Li}^{+} \mathrm{O}^{-}$nastalim zamjenom magnezijeva kationa litijevim u MgO. Warren ${ }^{52}$ je istraživao katalizatore koji sadrže barij i stroncij, ne bazične okside, te je u pojnu smjesu dodavao male količine etil-klorida. Utvrdio je da klorid poboljšava svojstva katalizatora zbog povećanja broja aktivnih mjesta (povećanje brzine konverzije $\mathrm{CH}_{4}$ ), smanjenja brzine razvijanja $\mathrm{CO}_{2}$ i povećanja omjera $\mathrm{C}_{2} \mathrm{H}_{4} / \mathrm{C}_{2} \mathrm{H}_{6} \mathrm{u}$ produktu. Warren pretpostavlja da etil-klorid reagira s katalizatorom dajući klorove radikale koji dehidrogeniraju etan u eten u plinskoj fazi. Dobivena su iskorištenja na $\mathrm{C}_{2}$ od 20 do $26 \%$. Dosad je istražen niz katalizatora za reakciju OCM koji se mogu grupirati na osnovi oksida: a) metala 4. i 5. skupine, b) metala 3. skupine, c) metala 2. skupine, d) metala 1. skupine, e) lantanida i d) prijelaznih metala. ${ }^{53,54} \mathrm{U}$ novije vrijeme zbog svojih svojstava i stabilnosti izdvaja se katalizator $\mathrm{Mn} / \mathrm{Na}_{2} \mathrm{WO}_{4} / \mathrm{SiO}_{2} .{ }^{55,56}$ lako je kompleksne strukture, $\mathrm{Mn} / \mathrm{Na}_{2} \mathrm{WO}_{4} / \mathrm{SiO}_{2}$ se pokazao kao dugotrajno stabilan katalizator za rad pri visokim temperaturama pri provedbi reakcija OCM. ${ }^{57-59}$ Navedenim katalizatorom postižu se konverzije od 20 do 30 \% sa selektivnošću od 70 do 80 \%. Provedene su također razne modifikacije navedenog katalizatora, prilikom čega je došlo do zamjene:

a) mangana $\rightarrow$ vanadijem, željezom, kobaltom, cinkom, ${ }^{60,61}$ cerijem $^{62}$

b) natrija $\rightarrow$ litijem, kalijem, barijem, željezom, kalcijem, kobaltom, niklom, aluminijem, ${ }^{63}$ te litijem, kalijem, rubidijem, cezijem, manganom i kalcijem ${ }^{64}$

c) volframa $\rightarrow$ ugljikom, silicijem, kositrom, fosforom, borom i sumporom, ${ }^{65}$ molibdenom, vanadijem, niodimijem, kromom ${ }^{66}$

d) skupine $\mathrm{WO}_{4} \rightarrow$ skupinama $\mathrm{MoO}_{4}, \mathrm{SO}_{4}, \mathrm{PO}_{4}, \mathrm{P}_{2} \mathrm{O}_{7}$

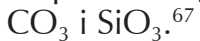

Za provedbu reakcije OCM i za odabir katalizatora presudan je odnos između selektivnosti katalizatora prema određenom produktu i konverzije metana. Kao rješenje problema niske konverzije nameće se recirkulacija metana. Međutim, separacija metana od ostalih produkata ekonomski je skup (nepovoljan) proces. Navedeni problem je inženjerske prirode pa su se s vremenom razvijali novi reaktori te načini dovođenja reaktanata i separacije produkata. Neka od rješenja su membranski reaktori, ${ }^{68-73}$ raspodjela dopreme kisika, ${ }^{74,75}$ elektrokatalitički-separacijski reaktori $^{76}$ i kromatografska separacija produkata. ${ }^{77}$

Drugi pristup poboljšanju reakcije OCM je zamjena oksidansa pa se umjesto molekulskog kisika najčešće upo- trebljava dušikov oksid $\left(\mathrm{N}_{2} \mathrm{O}\right) .^{78-81}$ Uporabom $\mathrm{N}_{2} \mathrm{O}$ pri istim eksperimentalnim uvjetima, u usporedbi s kisikom, povećala se selektivnost prema $C_{2}$. Istraživanja upućuju na to da su dobri procesni uvjeti za provedbu reakcije OCM visoka temperatura (>973 K) i katalizator na osnovi bazičnog metalnog oksida. Odabirom raznih katalizatora postižu se visoke selektivnosti s malim konverzijama, ili pak nešto veće konverzije s malim selektivnostima. Glavni termodinamički problem je manja stabilnost produkata $\mathrm{C}_{2} \mathrm{H}_{4}$ i $\mathrm{C}_{2} \mathrm{H}_{6}$ nego reaktanta $\mathrm{CH}_{4}$, zbog čega s vremenom dolazi do njihove oksidacije.

\section{Parcijalna oksidacija metana}

Parcijalnom oksidacijom metana (POM) može se doći do vrjednijih petrokemijskih produkata preko dvostupanjskog i jednostupanjskog procesa. Dvostupanjski proces sastoji se od pretvorbe metana u sintezni plin $\left(\mathrm{CO}+\mathrm{H}_{2}\right)$ i daljnje reakcije sinteznog plina $u$ razne produkte (slika 2 ). Jednostupanjski proces spada u izravne metode, a reakcija je primarno usmjerena na proizvodnju metanola i formaldehida (slika 9).

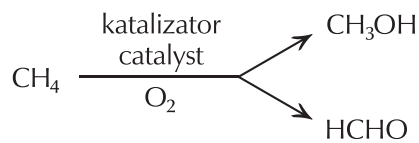

Slika 9 - Jednostupanjska reakcija POM

Fig. 9 - One-step partial oxidation of methane

Promatra li se reakcija POM s termodinamičkog gledišta očito je da je produkt višeg oksidacijskog stupnja termodinamički poželjniji (slika 10). Navedenim se objašnjava zašto je problem voditi reakciju POM do visokih konverzija i zašto koncentracija kisika u ulaznoj smjesi treba biti niska.

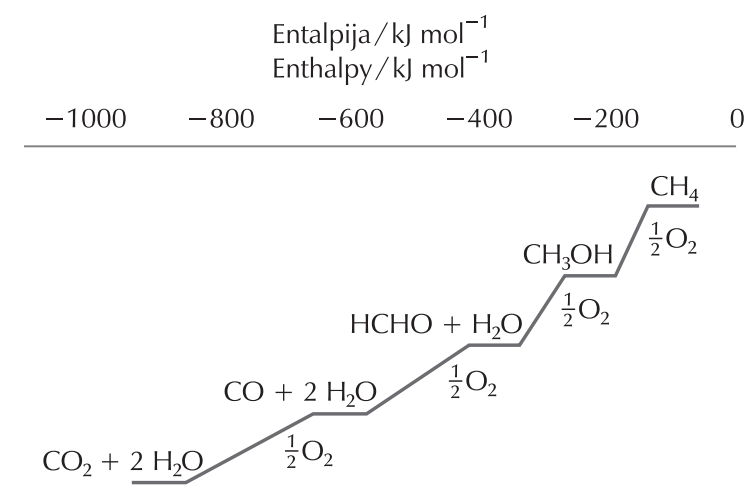

Slika 10 - Entalpije nastajanja produkata oksidacije metana Fig. 10 - Enthalpy of formation of methane oxidation products

Reakcija POM može biti katalitički i nekatalitički proces, pri čemu se u drugom procesu postiže veća selektivnost za metanol. Katalizatori koji se upotrebljavaju većinom su na osnovi silicija, zeolita, molibdena, vanadija, kompleksa, polioksometalata, fotokatalizatora i enzima. Pregled katalitičkih reakcija dan je u literaturi iz koje je preuzeta i tablica $1.82 \mathrm{U}$ nekatalitičkom procesu na rezultate reak- 
cije može utjecati sastav stijenke reaktora, prisustvo senzibilizatora (engl. sensitizer), tvari koje potiču druge tvari na (foto)kemijsku reakciju, i reakcijski uvjeti. Upotrebom reaktora s unutarnjom stijenkom od stakla Pyrex, teflona, nehrđajućeg čelika, srebra i bakra, Hunter $i$ sur. ${ }^{83}$ željeli su ispitati utjecaj tih tvari na reakciju POM. Njihov utjecaj na selektivnost metanola nije bio značajan, a selektivnost je bila $89,7 \pm 2,6 \%$ pri optimalnim temperaturama. U slučaju primjene nižih temperatura kod nekih stijenki došlo je do smanjenja selektivnosti. Zaključeno je da zbog spore difuzije radikala prema površini, pri eksperimentalnim uvjetima, stijenke nisu imale značajan utjecaj, a primjenom nižih temperatura došlo je do utjecaja na početni stupanj reakcije. Isti autori ispitivali su i utjecaj senzibilizatora na POM-reakciju, prilikom čega su upotrebljavali ugljikovodike (zasićene, nezasićene, cikličke, aromatske), spojeve s kisikom, tiole i amine. Dobili su čitav niz rezultata, pri čemu se selektivnost metanola i formaldehida značajno mijenjala. Uz tetrahidrofuran, 2,2,4-trimetilpentan, 2,3-dimetilbutan i 2,3-dimetil-but-2-en dobivena je veća pretvorba metana $u$ metanol i/ili formaldehid nego $u$ nesenzbiliziranoj reakciji, već i pri minimalnom dodatku navedenih tvari. Dodatak senzibilizatora značajno smanjuje temperaturu reakcije i povećava selektivnost prema metanolu i formaldehidu. Ipak, u većini slučajeva upotreba senzibilizatora za poboljšanje reakcije nije ekonomski isplativa.

Tablica 1 - Katalizatori i reakcijski uvjeti provedbe reakcije POM $^{82}$

Table 1 - Catalysts and reaction parameters for partial oxidation of methane ${ }^{82}$

\begin{tabular}{|c|c|c|c|c|c|c|}
\hline 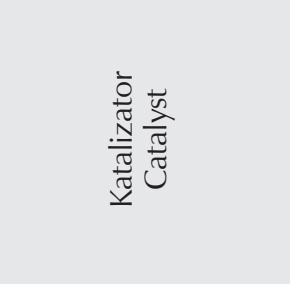 & 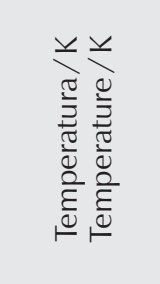 & 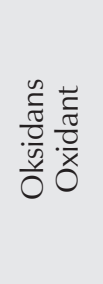 & 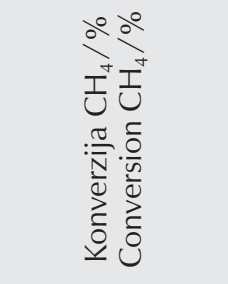 & 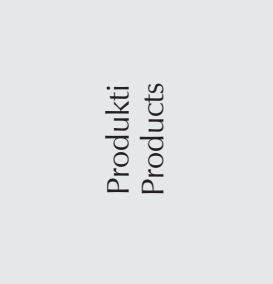 & 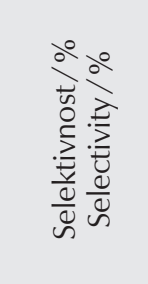 & 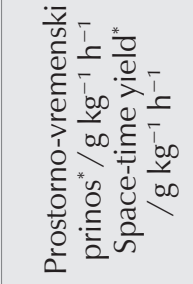 \\
\hline Nafion-H/Teflon/C & 393 & $\mathrm{H}_{2} \mathrm{O}_{2}$ & & $\mathrm{CH}_{3} \mathrm{OH}$ & 100 & 0,4 \\
\hline $\mathrm{MoO}_{3} / \mathrm{ZnO}$ & $493 / h v$ & $\mathrm{O}_{2}$ & 0,08 & $\mathrm{HCHO}$ & 81 & 0,6 \\
\hline $\mathrm{MoO}_{3} / \mathrm{SiO}_{2}$ & $493 / h v$ & $\mathrm{O}_{2}$ & 0,08 & $\mathrm{HCHO}$ & 97 & 7 \\
\hline $\mathrm{ZrP}$ & 973 & $\mathrm{O}_{2}$ & 2 & $\mathrm{HCHO}$ & 32,1 & 10,3 \\
\hline $\mathrm{SiO}_{2}$ & 793 & $\mathrm{O}_{2}$ & - & $\mathrm{HCHO}$ & 53 & 17,9 \\
\hline $\mathrm{MoO}_{3} / \mathrm{Fe}_{2} \mathrm{O}_{3} / \mathrm{SiO}_{2}$ & 873 & $\mathrm{~N}_{2} \mathrm{O}$ & 0,65 & $\mathrm{HCHO}$ & 20 & 20,9 \\
\hline $\mathrm{V}_{2} \mathrm{O}_{5} / \mathrm{SiO}_{2}$ & 873 & $\mathrm{~N}_{2} \mathrm{O}$ & 0,56 & $\mathrm{HCHO}$ & 26 & 22,8 \\
\hline $\mathrm{BeO} / \mathrm{B}_{2} \mathrm{O}_{3} / \mathrm{SiO}_{2}$ & 873 & $\mathrm{O}_{2}$ & 2,8 & $\mathrm{HCHO}$ & 32 & 24 \\
\hline $\mathrm{Cu} / \mathrm{Fe} / \mathrm{ZnO}$ & 1023 & $\mathrm{O}_{2}$ & 2,5 & $\mathrm{HCHO}$ & 10 & 76 \\
\hline $\mathrm{SiO}_{2}$ & 953 & $\mathrm{O}_{2}$ & 1,53 & $\mathrm{HCHO}$ & 40,2 & 77,7 \\
\hline $\mathrm{Mo}-\mathrm{Sn} / \mathrm{SiO}_{2}$ & 973 & $\mathrm{O}_{2}$ & 20 & $\mathrm{HCHO}$ & 80 & 80 \\
\hline $\mathrm{SiO}_{2}$ & 873 & $\mathrm{O}_{2}$ & 0,036 & $\mathrm{HCHO}$ & 75 & 116 \\
\hline $\mathrm{Sr} / \mathrm{La}_{2} \mathrm{O}_{3} / \mathrm{MoO}_{3} / \mathrm{SiO}_{2}$ & 903 & $\mathrm{O}_{2}$ & 8,2 & $\mathrm{HCHO}$ & 3,3 & 129 \\
\hline $\begin{array}{l}\text { Fe-sodalit } \\
\text { Fe-sodalite }\end{array}$ & 708 & $\mathrm{O}_{2}$ & 5,8 & $\mathrm{CH}_{3} \mathrm{OH}$ & 25 & 186 \\
\hline $\mathrm{Sr} / \mathrm{La}_{2} \mathrm{O}_{3} / \mathrm{MoO}_{3} / \mathrm{SiO}_{2}$ & 903 & $\mathrm{O}_{2}$ & 6,7 & $\mathrm{HCHO}$ & 4,1 & 186,7 \\
\hline $\mathrm{MgO}$ & 1023 & $\mathrm{O}_{2}$ & 0,7 & $\mathrm{HCHO}$ & 60 & 270 \\
\hline $\mathrm{SiO}_{2}$ & 923 & $\mathrm{O}_{2}$ & 0,11 & $\mathrm{HCHO}$ & 63 & 304 \\
\hline $\mathrm{V}_{2} \mathrm{O}_{5} / \mathrm{SiO}_{2}$ & 873 & $\mathrm{O}_{2}$ & 0,151 & $\mathrm{HCHO}$ & 48 & 218 \\
\hline $\mathrm{Cu}-\mathrm{Fe} \times \mathrm{ZSM}-5$ & 615 & $\mathrm{~N}_{2} \mathrm{O}$ & 1,12 & $\mathrm{CH}_{3} \mathrm{OH}+\mathrm{HCHO}$ & $50+6,2$ & $347+40$ \\
\hline $\mathrm{Mo} / 2 \mathrm{Su} / \mathrm{P}$ & 948 & $\mathrm{O}_{2}$ & 7,2 & $\mathrm{HCHO}$ & 64,8 & 400 \\
\hline $\mathrm{CuO} \times \mathrm{MoO}_{3}$ & 758 & $\mathrm{O}_{2}$ & 1,4 & $\begin{array}{l}\text { oksigenati } \\
\text { oxygenates }\end{array}$ & 79 & 490 \\
\hline $\mathrm{V}_{2} \mathrm{O}_{5} / \mathrm{SiO}_{2}$ & 923 & $\mathrm{O}_{2}$ & 13,5 & $\mathrm{HCHO}$ & 35 & 760 \\
\hline $\mathrm{V}_{2} \mathrm{O}_{5} / \mathrm{SiO}_{2}$ & 923 & $\mathrm{O}_{2}$ & $0,521-0,078$ & $\mathrm{HCHO}$ & $35-48$ & $793-819$ \\
\hline $\mathrm{SiO}_{2}$ & 1053 & $\mathrm{O}_{2}$ & 0,68 & $\mathrm{HCHO}$ & 28 & 812,8 \\
\hline$\left(\mathrm{MoO}_{3}\right)_{3} \times \mathrm{Fe}_{2} \mathrm{O}_{3}$ & 712 & $\mathrm{O}_{2}$ & 2,1 & $\mathrm{CH}_{3} \mathrm{OH}+\mathrm{HCHO}$ & $65+8$ & $869+100$ \\
\hline $\mathrm{FeNbO}$ & 1143 & $\mathrm{O}_{2}$ & 2,15 & $\mathrm{HCHO}$ & 61,6 & 1210 \\
\hline
\end{tabular}

* omjer mase produkta i umnoška mase katalizatora i vremena

* product mass divided by product of catalyst mass and time 
Nadalje, istraživanja upućuju da povećanje temperature značajno smanjuje selektivnost prema metanolu. Visoke koncentracije kisika smanjuju selektivnost prema metanolu, ali povećavaju konverziju i iskorištenje na metanolu. Povećanje tlaka povećava selektivnost prema metanolu i konverziju metana. ${ }^{83-85}$

\section{Zaključak}

Reakcije izravne pretvorbe metana zahtijevaju selektivno kidanje jedne ili dviju veza $\mathrm{C}-\mathrm{H}$ u metanu, što otežava pronalaženje optimalnih reakcijskih uvjeta (temperature, tlaka, katalizatora, udjela oksidansa...), dok su u slučaju provođenja neizravne pretvorbe, gdje dolazi do kidanja svih veza metana, ograničenja mnogo manja. Zbog toga su parno reformiranje i piroliza metana komercijalno prihvatljiviji postupci u odnosu na neoksidacijske postupke dehidroaromatizacije metana, neoksidacijsko (NOCM) i oksidacijsko (OCM) spajanje metana u više ugljikovodike i parcijalnu oksidaciju metana. Oksidacijski postupci izravne pretvorbe su termodinamički povoljniji od neoksidacijskih postupaka, pa su povijesno privlačili više pažnje, a samim time provedeno je i više istraživanja na tom području.

Neoksidacijsko spajanje metana u više ugljikovodike je dvostupanjski (jednostupanjski) proces u kojem dolazi do adsorpcije metana na katalizator te desorpcije viših ugljikovodika uz pomoć vodika. Navedenim procesom postižu se niske konverzije metana koje se provođenjem procesa u plazmi mogu značajno povećati, ali je energetska učinkovitost niska. Jednostupanjski proces neoksidacijske dehidroaromatizacije metana termodinamički je povoljniji od NOCM-a, a reakcija se najčešće provodi na zeolitnom katalizatoru HZSM-5 koji sadrži molibdenove čestice. Nažalost, prilikom reakcije uspostavlja se termodinamička ravnoteža pri kojoj teorijsko iskorištenje pri $973 \mathrm{~K}$ iznosi oko $11 \%$, dok su eksperimentalna iskorištenja niža. Odvođenjem vodika u membranskim reaktorima konverzija se može povećati.

U slučaju reakcije OCM, mijenjanjem katalizatora može se dobiti veća konverzija metana ili veća selektivnost na ugljikovodicima $\mathrm{C}_{2+}$. Međutim nisu postignute vrijednosti $25 \%$ za konverziju i $80 \%$ za selektivnost, potrebne za isplativu komercijalnu primjenu. Postizanje komercijalne isplativosti provedbe reakcije OCM najvjerojatnije će biti usmjereno $k$ razvoju novih inženjerskih rješenja izvedbe procesa.

Jednostupanjska parcijalna oksidacija metana u metanol, iako privlačna zbog smanjenja energetske potrošnje s obzirom na dvostupanjski proces, nije dostigla svoju zrelost te se potraga za dovoljno aktivnim i selektivnim katalizatorom nastavlja.

\section{Popis kratica \\ List of abbreviations}

DTG - pretvorba dimetil-etera u benzin

- dimethyl ether to gasoline conversion

DTO - pretvorba dimetil-etera u olefine

- dimethyl ether to olefins conversion

$\begin{array}{ll}\text { MDA } & \text { - neoksidacijska dehidroaromatizacija metana } \\ & \text { - nonoxidative methane dehydroaromatization } \\ \text { MTG } & \text { - pretvorba metanola u benzin } \\ & \text { - methanol to gasoline conversion } \\ \text { MTO } & \text { - pretvorba metanola u olefine } \\ & \text { - methanol to olefins conversion } \\ \text { NOCM } & \text { - neoksidacijsko spajanje metana } \\ & \text { - nonoxidative coupling of methane } \\ \text { OCM } \quad \text { - oksidacijsko spajanje metana } & \\ \text { POM } & \text { - oxidative coupling of methane } \\ & \text { - parcijalna oksidacija metana } \\ \text { STD } & \text { - pretvorbal oxidation of methane } \\ & \text { - syngas to dimethyl ether conversion }\end{array}$

\section{Literatura \\ References}

1. Z. Janović, Naftni i petrokemijski procesi i proizvodi, Hrvatsko društvo za goriva i maziva, Zagreb, 2011.

2. Global Gas Flaring Reduction, Report, World Bank Group, 2004.

3. R. H. Crabtree, The organometallic chemistry of alkanes, Chem. Rev. 85 (1985) 245-269, http://dx.doi.org/10.1021/ cr00068a002.

4. R. G. Bergman, Activation of Alkanes with Organotransition Metal Complexes, Science 223 (1984) 902-908, http://dx. doi.org/10.1126/science.223.4639.902.

5. A. E. Shilov, Sov. Sci. Rev. Sect. B: Chem. Rev. 84 (1982) 71.

6. R. H. Crabtree, E. M. Holt, M. Lavin, S. M. Morekous, Inter- vs. intramolecular carbon-hydrogen activation: A carbon-hydrogen-iridium bridge in $\left[\mathrm{IrH}_{2}\right.$ (8-methylquinoline) $\left.\mathrm{L}_{2}\right]$ $\mathrm{BF}_{4}$ and a $\mathrm{C}-\mathrm{H}+\mathrm{M} \rightarrow \mathrm{C}-\mathrm{M}-\mathrm{H}$ reaction trajectory, Inorg. Chem. 24 (1985) 1986-1992, http://dx.doi.org/10.1021/ ic00207a008.

7. K. K. Irikura, J. L. Beauchamp, Methane oligomerization in the gas phase by third-row transition-metal ions, J. Am. Chem. Soc. 113 (1991) 2769-2770, http://dx.doi.org/10.1021/ ja00007a070.

8. H. Schwarz, Activation of Methane, Angew. Chem. 30 (1991) 820-821, http://dx.doi.org/10.1002/anie.199108201.

9. R. N. Patel, C. T. Hou, A. I. Laskin, A. Felix, P. Derelanko, Oxidation of alkanes by organisms grown on $C_{2}-C_{4}$ alkanes, J. Appl. Biochem. 5 (1983) 107-120.

10. M. Baerns, Methane - A Chemical Feedstock?, Nachr. Chem. Tech. Lab. 33 (1985) 292, http://dx.doi.org/10.1002/ nadc. 19850330405

11. R. Pitchai, K. Klier, Partial Oxidation of Methane, Catal. Rev.-Sci. Eng. 28 (1986) 13-88, http://dx.doi. org/10.1080/03602458608068085.

12. J. R. Anderson, Methane to higher hydrocarbons, Appl. Catal. 47 (1989) 177-196, http://dx.doi.org/10.1016/ S0166-9834(00)83227-3.

13. G. A. Olah, From Boron Trifluoride to Antimony Pentafluoride in Search of Stable Carbocations, Top. Curr. Chem. 80 (1979) 19-88, http://dx.doi.org/10.1007/BFb0050202.

14. G. A. Olah, D. G. Parker, N. Yoneda, Oxyfunctionalization of Hydrocarbons. 9. Superacid Catalyzed Oxygenation of Alkanes, Angew. Chem. 17 (1978) 909, http://dx.doi. org/10.1002/anie.197809091.

15. T. Koerts, M. T.A. G. Deelen, R. A. van Santen, Hydrocarbon 
formation from methane by a low-temperature two-step reaction sequence, J. Catal. 138 (1992) 101, http://dx.doi. org/10.1016/0021-9517(92)90010-F.

16. M. Belgued, P. Pareja, A. Amariglio, H. Amariglio, Conversion of methane into higher hydrocarbons on platinum, Nature 352 (1991) 789-790, http://dx.doi.org/10.1038/352789a0.

17. P. Pareja, A. Amariglio, M. Belgued, H. Amariglio, Increasing the yield in methane homologation through an isothermal two-reaction sequence at $250^{\circ} \mathrm{C}$ on platinum, Catal. Today 21 (1994) 423-430, http://dx.doi.org/10.1016/09205861(94)80164-9.

18. H. Amariglio, P. Pareja, A. Amariglio, Periodic operation of a catalyst as a means of overcoming a thermodynamic constraint. The case of methane homologation on metals, Catal. Today 25 (1995) 113, http://dx.doi.org/10.1016/09205861(95)00102-L.

19. H. Amariglio, M. Belgued, P. Pareja, A. Amariglio, Carbon monoxide induced desorption of alkanes and alkenes up to $\mathrm{C}_{8}$ after chemisorption of methane on platinum, Catal. Lett. 31 (1995) 19-26, http://dx.doi.org/10.1007/BF00817029.

20. M. Belgued, A. Amariglio, P. Pareja, H. Amariglio, Oxygen-Free Conversion of Methane to Higher Alkanes through an Isothermal Two-Step Reaction on Platinum (EUROPT-1): I. Chemisorption of Methane, J. Catal. 159 (1996) 441-448, http://dx.doi.org/10.1006/jcat.1996.0108.

21. M. Belgued, A. Amariglio, P. Pareja, H. Amariglio, Oxygen-Free Conversion of Methane to Higher Alkanes through an Isothermal Two-Step Reaction on Platinum (EUROPT-1): II. Hydrogenation of the Adspecies Resulting from the Chemisorption of Methane, J. Catal. 159 (1996) 449-457, http://dx.doi.org/10.1006/jcat.1996.0109.

22. M. Belgued, A. Amariglio, L. Lefort, P. Pareja, H. Amariglio, Oxygen-Free Conversion of Methane to Higher Alkanes through an Isothermal Two-Step Reaction on Ruthenium, J. Catal. 161 (1996) 282-291, http://dx.doi.org/10.1006/ jcat.1996.0186.

23. F. Solymosi, A. Erdohelyi, J. Cserenyi, A. Felvegi, Decomposition of $\mathrm{CH}_{4}$ over Supported Pd Catalysts, J. Catal. 147 (1994) 272-278, http://dx.doi.org/10.1006/jcat.1994.1138.

24. F. Solymosi, J. Cserenyi, Enhanced formation of ethane in the conversion of methane over $\mathrm{Cu}-\mathrm{Rh} / \mathrm{SiO}$, Catal. Lett. 34 (1995) 343-350, http://dx.doi.org/10.1007/BF00806883.

25. L. Guczi, K. V. Sarma, L. Borko, Low-Temperature Methane Activation under Nonoxidative Conditions over Supported Ruthenium-Cobalt Bimetallic Catalysts, J. Catal. 167 (1997) 495-502, http://dx.doi.org/10.1006/jcat.1997.1605.

26. L. Guczi, K. V. Sarma, L. Borko, Non-oxidative methane coupling over Co-Pt/NaY bimetallic catalysts, Catal. Lett. 39 (1996) 43-47, http://dx.doi.org/10.1007/BF00813728.

27. T. Koerts, P. A. Leclercq, R. A. van Santen, Homologation of olefins with methane on transition metals, J. Am. Chem. Soc. 114 (1992) 7272-7278, http://dx.doi.org/10.1021/ ja00044a043.

28. M. C. J. Bradford, Isothermal, non-oxidative, two-step $\mathrm{CH}_{4}$ conversion over unsupported and supported $\mathrm{Ru}$ and $\mathrm{Pt}$ catalysts, Catal. Lett. 66 (2000) 113-120, http://dx.doi. org/10.1023/A:1019064026593.

29. L. Guczi, L. Borkó, Zs. Koppány, F. Mizukami, Effect of hydrogen on methane conversion to hydrocarbons in "onestep" $^{\prime \prime}$ reaction under non-oxidative conditions at low temperature over $\mathrm{Pd}-\mathrm{Co} / \mathrm{SiO}_{2}$ catalysts prepared by the sol/ gel method, Catal. Lett. 54 (1998) 33-39, http://dx.doi. org/10.1023/A:1019011518338.

30. L. Guczi, L. Borko, Zs. Koppany, I. Kiricsi, "One-Step" Methane conversion under non oxidative conditions over Pt-Co/
NaY catalysts at low temperature, Stud. Surf. Sci. Catal. 119 (1998) 295-300, http://dx.doi.org/10.1016/S01672991(98)80447-3.

31. L. Guczi, L. Borko, Comparative study on hydrogen-assisted "one-step" methane conversion over $\mathrm{Pd}-\mathrm{Co} / \mathrm{SiO}_{2}$ and Pt-Co/NaY catalysts, Catal. Today 64 (2001) 91-96, http:// dx.doi.org/10.1016/S0920-5861(00)00512-5.

32. S. Kado, Y. Sekine, K. Fujimoto, Direct synthesis of acetylene from methane by direct current pulse discharge, Chem. Commun. 24 (1999) 2485-2486, http://dx.doi.org/10.1039/ a906914c.

33. A. Zhu, W. Gong, X. Zhang, B. Zhang, Coupling of methane under pulse corona plasma (I), Sci. China 43 (2000) 208214, http://dx.doi.org/10.1007/BF03027312.

34. Y. Xu, Z. Tian, Z. Xu, A. Zhu, L. Lin, Methane conversion via microwave plasma initiated by a metal initiator, Stud. Surf. Sci. Catal. 136 (2001) 75-80, http://dx.doi.org/10.1016/ S0167-2991(01)80283-4.

35. A. B. Redondo, E. Troussard, J. A. van Bokhoven, Non-oxidative methane conversion assisted by corona discharge, Fuel Process. Technol. 104 (2012) 265-270, http://dx.doi. org/10.1016/j.fuproc.2012.05.021.

36. L. Wang, L. Tao, M. Xie, G. Xu, J. Huang, Y. Xu, Dehydrogenation and aromatization of methane under non-oxidizing conditions, Catal. Lett. 21 (1993) 35-41, http://dx.doi. org/10.1007/BF00767368.

37. L. Y. Chen, L. W. Lin, Z. S. Xu, X. S. Li, T. Zhang, Dehydro-oligomerization of Methane to Ethylene and Aromatics over Molybdenum/HZSM-5, Catalyst J. Catal. 157 (1995) 190200, http://dx.doi.org/10.1006/jcat.1995.1279.

38. Y. Xu, S. Liu, L. Wang, M. Xie, X. Guo, Methane activation without using oxidants over Mo/HZSM-5 zeolite catalysts, Catal. Lett. 30 (1994) 135-149, http://dx.doi.org/10.1007/ BF00813680.

39. F. Solymosi, A. Erdohelyi, A. Szoke, Dehydrogenation of methane on supported molybdenum oxides. Formation of benzene from methane, Catal. Lett. 32 (1995) 43-53, http:// dx.doi.org/10.1007/BF00806100.

40. F. Solymosi, A. Szoke, Selective oxidation of methane to benzene over $\mathrm{K}_{2} \mathrm{MoO}_{4} / \mathrm{ZSM}-5$ catalysts, Appl. Catal. A 142 (1996) 361-374, http://dx.doi.org/10.1016/0926860X(96)00085-3.

41. F. Solymosi, A. Szoke, J. Cserenyi, Conversion of methane to benzene over $\mathrm{Mo}_{2} \mathrm{C}$ and $\mathrm{Mo}_{2} \mathrm{C} / \mathrm{ZSM}-5$ catalysts, Catal. Lett. 39 (1996) 157-161, http://dx.doi.org/10.1007/ BF00805576.

42. F. Solymosi, J. Cserenyi, A. Szoke, T. Bansagi, A. Dszko, Aromatization of Methane over Supported and Unsupported Mo-Based Catalysts, J. Catal. 165 (1997) 150-161, http:// dx.doi.org/10.1006/jcat.1997.1478.

43. B. M. Weckhuysen, D. Wang, M. P. Rosynek, J. H. Lunsford, Conversion of Methane to Benzene over Transition Metal Ion ZSM-5 Zeolites: I. Catalytic Characterization, J. Catal. 175 (1998) 338-346, http://dx.doi.org/10.1006/jcat.1998.2010.

44. L. Wang, Y. Xu, M. Xie, S. Liu, L. Tao, Activation and aromatization of methane and ethane over Mo(VI)/HZSM-5 and W(VI)/HZSM-5 zeolites catalysts, Stud. Surf. Sci. Catal. 94 (1995) 495-500, http://dx.doi.org/10.1016/S01672991(06)81260-7.

45. L. Wang, Y. Xu, S. T. Wong, W. Cui, X. Guo, Activity and stability enhancement of $\mathrm{Mo} / \mathrm{HZSM}$-5-based catalysts for methane non-oxidative transformation to aromatics and $\mathrm{C}_{2}$ hydrocarbons: Effect of additives and pretreatment conditions, Appl. Catal. A 152 (1997) 173-182, http://dx.doi.org/10.1016/ S0926-860X(96)00366-3. 
46. S. Liu, Q. Dong, R. Ohnishi, M. Ichikawa, Remarkable non-oxidative conversion of methane to naphthalene and benzene on $\mathrm{Co}$ and Fe modified Mo/HZSM-5 catalysts, Chem. Commun. (1997) 1455-1456, http://dx.doi. org/10.1039/a702731a.

47. S. T. Wong, Y. Xu, L. Wang, S. Liu, G. Li, M. Xie, X. Guo, Methane and ethane activation without adding oxygen: promotional effect of W in Mo-W/HZSM-5, Catal. Lett. 38 (1996) 39-43, http://dx.doi.org/10.1007/BF00806897.

48. Y. Schuurman, C. Mirodatos, Uses of transient kinetics for methane activation studies, Appl. Catal. A 151 (1997) 305331, http://dx.doi.org/10.1016/S0926-860X()/)00031-8.

49. L. B. Pierella, L. Wang, O. A. Anunziata, Methane direct conversion to aromatic hydrocarbons at low reaction temperature, React. Kinet. Catal. Lett. 60 (1997) 101-106, http:// dx.doi.org/10.1007/BF02477696.

50. G. F. Keller, M. Bhasin, Synthesis of ethylene via oxidative coupling of methane: I. Determination of active catalysts, J. Catal. 73 (1982) 9-19, http://dx.doi.org/10.1016/00219517(82)90075-6.

51. T. Ito, J. H. Lunsford, Synthesis of ethylene and ethane by partial oxidation of methane over lithium-doped magnesium oxide, Nature 314 (1985) 721-722, http://dx.doi. org/10.1038/314721b0.

52. B. K. Warren, The role of chlorine in chlorine-promoted methane coupling catalysts, Catal. Today 13 (1992) 311 320, http://dx.doi.org/10.1016/0920-5861(92)80155-G.

53. J. H. Lunsford, Catalytic conversion of methane to more useful chemicals and fuels: a challenge for the 21st century, Catal. Today 63 (2000) 165-174, http://dx.doi.org/10.1016/ S0920-5861(00)00456-9.

54. M. Baerns, O. V. Buyevskaya, Catalytic oxidative conversion of alkanes to olefins and oxygenates, Erdöl Erdgas Kohle 116 (2000) 25-30.

55. S. B. Li, Oxidative Coupling of Methane over $\mathrm{W}-\mathrm{Mn} / \mathrm{SiO}_{2}$, Catalys, Chin. J. Chem. 19 (2001) 16-21, http://dx.doi. org/10.1002/cjoc.20010190104.

56. S. B. Li, Reaction Chemistry of $\mathrm{W}-\mathrm{Mn} / \mathrm{SiO}_{2}$ Catalyst for the Oxidative Coupling of Methane, J. Nat. Gas Chem. 12 (2003) 1-9.

57. U. Simon, O. Gorke, A. Berthold, S. Arndt, R. Schomacker, $H$. Schubert, Fluidized bed processing of sodium tungsten manganese catalysts for the oxidative coupling of methane, Chem. Eng. J. 168 (2011) 1352-1359, http://dx.doi. org/10.1016/j.cej.2011.02.013.

58. S. Pak, P. Qiu, J. H. Lunsford, Elementary Reactions in the Oxidative Coupling of Methane over $\mathrm{Mn} / \mathrm{Na}_{2} \mathrm{WO}_{4} / \mathrm{SiO}_{2}$ and $\mathrm{Mn} / \mathrm{Na}_{2} \mathrm{WO}_{4} / \mathrm{MgO}$ Catalysts, J. Catal. 179 (1998) 222-230, http://dx.doi.org/10.1006/jcat.1998.2228.

59. H. T. Liu, X.L. Wang, D. X. Yang, R. X. Gao, Z. L. Wang, J. Yang, Scale up and stability test for oxidative coupling of methane over $\mathrm{Na}_{2} \mathrm{WO}_{4}-\mathrm{Mn} / \mathrm{SiO}_{2}$ catalyst in a $200 \mathrm{ml}$ fixed-bed reactor, J. Nat. Gas Chem. 17 (2008) 59-63, http://dx.doi. org/10.1016/S1003-9953(08)60026-2.

60. A. Malekzadeh, A. Khodadadi, M. Abedini, M. Amini, A. Bahramian, A. K. Dalai, Correlation of electrical properties and performance of OCM MO $\mathrm{O} / \mathrm{Na}_{2} \mathrm{WO}_{4} / \mathrm{SiO}_{2}$ catalysts, Catal. Commun. 2 (2001) 241-247, http://dx.doi.org/10.1016/ S1566-7367(01)00034-6.

61. A. Malekzadeh, A. K. Dalai, A. Khodadadi, Y. Mortazavi, Structural features of $\mathrm{Na}_{2} \mathrm{WO}_{4}-\mathrm{MO}_{x} / \mathrm{SiO}_{2}$ catalysts in oxidative coupling of methane reaction, Catal. Commun. 9 (2008) 960-965, http://dx.doi.org/10.1016/j.catcom.2007.09.026.

62. Z. Gholipour, A. Malekzadeh, R. Hatami, Y. Mortazavi, A. Khodadadi, Oxidative coupling of methane over
$\left(\mathrm{Na}_{2} \mathrm{WO}_{4}+\mathrm{Mn}\right.$ or $\left.\mathrm{Ce}\right) / \mathrm{SiO}_{2}$ catalysts: In situ measurement of electrical conductivity, J. Nat. Gas Chem. 19 (2010) 35, http://dx.doi.org/10.1016/S1003-9953(09)60028-1.

63. S. F. Ji, T. C. Xiao, S. B. Li, L. J. Chou, B. Zhang, C. Z. Xu, R. L. Hou, A. P. E. York, M. L. H. Green, Surface $\mathrm{WO}_{4}$ tetrahedron: the essence of the oxidative coupling of methane over M-W-Mn/SiO catalysts, J. Catal. 220 (2003) 47-56, http:// dx.doi.org/10.1016/S0021-9517(03)00248-3.

64. A. Palermo, J. P. Holgado Vazquez, R. M. Lambert, New efficient catalysts for the oxidative coupling of methane, Catal. Lett. 68 (2000) 191-196, http://dx.doi. org/10.1023/A:1019072512423.

65. Z. Q. Yu, X. M. Yang, J. H. Lunsford, M. P. Rosynek, Oxidative Coupling of Methane over $\mathrm{Na}_{2} \mathrm{WO}_{4} / \mathrm{CeO}_{2}$ and Related Catalysts, J. Catal. 154 (1995) 163-173, http://dx.doi. org/10.1006/jcat.1995.1157.

66. S. Mahmoodi, M. R. Ehsani, S. M. Goreishi, Effect of promoter in the oxidative coupling of methane over synthesized $\mathrm{Mn} / \mathrm{SiO}_{2}$ nanocatalysts via incipient wetness impregnation, J. Ind. Eng. Chem. 16 (2010) 923-928, http://dx.doi. org/10.1016/j.jiec.2010.09.007.

67. S. C. Hou, Y. Cao, W. Xiong, H. C. Liu, Y. Kou, Site Requirements for the Oxidative Coupling of Methane on $\mathrm{SiO}_{2}$-Supported Mn Catalysts, Ind. Eng. Chem. Res. 45 (2006) 7077 7083, http://dx.doi.org/10.1021/ie060269c.

68. Y. S. Lin, Y. Zeng, Catalytic Properties of Oxygen Semipermeable Perovskite-Type Ceramic Membrane Materials for Oxidative Coupling of Methane, J. Catal. 164 (1996) 220-231, http://dx.doi.org/10.1006/jcat.1996.0377.

69. Y. Zeng, Y. S. Lin, Oxygen Permeation and Oxidative Coupling of Methane in Yttria Doped Bismuth Oxide Membrane Reactor, J. Catal. 193 (2000) 58-64, http://dx.doi.org/10.1006/ jcat.2000.2876

70. Y. Lu, A. G. Dixon, W. R. Moser, Y. H. Ma, U. Balachandran, Oxidative coupling of methane using oxygen-permeable dense membrane reactors, Catal. Today 56 (2000) 297-305, http://dx.doi.org/10.1016/S0920-5861(99)00287-4.

71. D. Lafarga, J. Santamaria, M. Menendez, Methane oxidative coupling using porous ceramic membrane reactors - I. reactor development, Chem. Eng. Sci. 49 (1994) 2005-2013, http://dx.doi.org/10.1016/0009-2509(94)80083-9.

72. Y. Lu, A. G. Dixon, W. R. Moser, Y. H. Ma, Oxidative coupling of methane in a modified $\gamma$-alumina membrane reactor, Chem. Eng. Sci. 55 (2000) 4901-4912, http://dx.doi. org/10.1016/S0009-2509(00)00121-4.

73. Y. Lu, A. G. Dixon, W. R. Moser, Y. H. Ma, U. Balachandran, Oxygen-permeable dense membrane reactor for the oxidative coupling of methane, J. Membrane Sci. 170 (2000) 27-34, http://dx.doi.org/10.1016/S0376-7388(99)00354-3.

74. V. R. Choudhary, S. T. Chaudhari, A. M. Rajput and V. H. Rane, Beneficial effect of oxygen distribution on methane conversion and $\mathrm{C}_{2}$-selectivity in oxidative coupling of methane to $\mathrm{C}_{2}$-hydrocarbons over lanthanum-promoted magnesium oxide, J. Chem. Soc. Chem. Commun. 20 (1989) 1526-1527, http://dx.doi.org/10.1039/c39890001526.

75. J. A. Santamaria, M. Menendez, J. A. Pena, J. I. Barahona, Methane oxidative coupling in fixed bed catalytic reactors with a distributed oxygen feed. A simulation study, Catal. Today 13 (1992) 353-360, http://dx.doi.org/10.1016/09205861(92)80160-O.

76. M. Makri, Y. Jiang, I. V. Yentekakis, C. G. Vayenas, Oxidative coupling of methane to ethylene with 85 yield in a gas recycle electrocatalytic or catalytic reactor-separator, Stud. Surf. Sci. Catal. 101 (1996) 387-396, http://dx.doi.org/10.1016/ S0167-2991(96)80249-7. 
77. A. L. Tonkovich, R. W. Carr, R. W. Aris, Enhanced $\mathrm{C}_{2}$ Yields from Methane Oxidative Coupling by Means of a Separative Chemical Reactor, Science 262 (1993) 221-223, http://dx. doi.org/10.1126/science.262.5131.221.

78. K. Otsuka, T. Nakajima, Oxidative coupling of methane over samarium oxides using $\mathrm{N}_{2} \mathrm{O}$ as the oxidant, J. Chem. Soc. Faraday Trans. I 83 (1987) 1315-1321, http://dx.doi. org/10.1039/f19878301315.

79. G. J. Hutchings, M. S. Scurrell, J. R. Woodhouse, The role of surface $\mathrm{O}^{-}$in the selective oxidation of methane, J. Chem. Soc. Chem. Commun. (1987) 1388-1389, http://dx.doi. org/10.1039/c39870001388.

80. G. J. Hutchings, M. S. Scurrell, J. R. Woodhouse, Partial oxidation of methane using oxide catalysts: Comments on the reaction mechanism, J. Chem. Soc. Faraday Trans. I 85 (1989) 2507-2523, http://dx.doi.org/10.1039/f19898502507.

81. H. Yamamoto, H. Y. Chu, M. Xu, C. Shi, J. H. Lunsford, Oxidative Coupling of Methane over a $\mathrm{Li}^{+} / \mathrm{MgO}$ Catalyst Using $\mathrm{N}_{2} \mathrm{O}$ as an Oxidant, J. Catal. 142 (1993) 325-336, http:// dx.doi.org/10.1006/jcat.1993.1211.
82. R. W. Joyner, S. H. Taylor, T. J. Hall, J. S. J. Hargreaves, G. J. Hutchings, Catalytic synthesis of methanol and formaldehyde by partial oxidation of methane, Fuel Process. Technol. 42 (1995) 151-178, http://dx.doi.org/10.1016/03783820(94)00125-D.

83. N. R. Hunter, H. D. Gesser, L. A. Morton, P. S. Yarlagadda, Methanol formation at high pressure by the catalyzed oxidation of natural gas and by the sensitized oxidation of methane, Appl. Catal. 57 (1990) 45-54, http://dx.doi. org/10.1016/S0166-9834(00)80722-8.

84. D. W. Rytz, A. Baiker, Partial oxidation of methane to methanol in a flow reactor at elevated pressure, Ind. Eng. Chem. Res. 30 (1991) 2287-2292, http://dx.doi.org/10.1021/ ie00058a007.

85. G. A. Foulds, B. F. Gray, S. A. Miller, G. S. Walker, Homogeneous gas-phase oxidation of methane using oxygen as oxidant in an annular reactor, Ind. Eng. Chem. Res. 32 (1993) 780-787, http://dx.doi.org/10.1021/ie00017a003.

\title{
SUMMARY
}

\section{New Petrochemical Processes Based on Direct Conversion of Methane \\ Fabio Faraguna and Ante Jukić*}

\begin{abstract}
Petrochemistry is a branch of chemistry and chemical engineering that studies reactions and processes of the transformation of petroleum derivatives and natural gas into useful petrochemicals. In its beginning, petrochemistry, or rather the organic chemical industry, was based on the acetylene and Reppe chemistry. The main raw materials of the petrochemical industry nowadays are olefins and aromatic hydrocarbons, with a pronounced tendency toward development of new processes and higher usage of syngas, methane and other alkanes. Here, the reactions and new processes of direct conversion of methane into more valuable petrochemicals are reviewed. Reactions of partial oxidation of methane, dehydroaromatization of methane, oxidative and non-oxidative coupling of methane to higher hydrocarbons are also described and discussed.
\end{abstract}

\section{Keywords}

Direct conversion, methane, new petrochemical processes

Department of Petroleum Refining

Review

and Petrochemistry

Faculty of Chemical Engineering

and Technology

University of Zagreb

Marulićev trg 19

10000 Zagreb, Croatia

Received November 26, 2013

Accepted February 4, 2014 